\title{
Near Pandemic state of Influenza A (H1N1) virus, economic contraction (read depression) and the state of Mental Health \& Addiction Services
}

\author{
Masood Zangeneh
}

Received: 8 May 2009 / Accepted: 8 May 2009 /

Published online: 27 May 2009

(C) Springer Science + Business Media, LLC 2009

Family physicians are the first point of contact for anyone who wishes to access mental health or addiction services in Canada. A chronic shortage of front line family doctors in Canada and other countries around the world, however, makes it extremely hard, if not impossible, for desperate end users to seek help. During this near pandemic period of swine influenza, Mental Health and Addiction service issues are at risk of being overlooked as a genuine public health crisis intersects with mass hysteria driven by constant media coverage.

The dismal state of health research, service availability and access to care in countries like Canada is embarrassing, if not inhuman. Currently, billions of dollars are being pumped into the coffers of private corporations such as banks, automobile manufacturers and investment companies. At the same time, under funded rudimentary health programs are being asked to claw back on expenditures. Thus, health care providers are essentially bearing the brunt for the poor decisions made by the private sector and their failed pursuits of ever-increasing profits.

As a result, hospital budgets are being slashed, making life for the most vulnerable members of society more difficult as they attempt to obtain the most basic care. It is a shame that countries such as the United States and Canada, with their outrageous defense expenditures, are failing to secure the most basic of human rights for their citizensnamely, the right to the medical treatment. Ironically, the tiny island of Cuba produces such an excess of doctors per capita that their physicians have filled the void in the international medical community.

To complicate matters further, the neglect of basic medical need also acts as an extended de facto for Mental Health and Addiction necessities, as funds gets diverted to other "urgent" administrative matters. Consequently, this could result in the further marginalizing of the already peripheralized mental health and addiction programs and services that are in existence.

M. Zangeneh $(\bowtie)$

International Journal of Mental Health \& Addiction (IJMA), Editorial Office, 54 Royal Chapin Crescent, Richmond Hill, ON L4S 2A7, Canada

e-mail: masood.zangeneh@utoronto.ca 
So, what is the solution? Many have suggested privatization as a possible solution to the lack of health care accessibility. Privatization, however, has consistently proven to be ineffective and disadvantageous to marginalized groups, putting them at further risk. There are numerous examples of such tragedy. For example, last year covert privatization of food and health safety checks in Canada came to a head at Maple Leaf Foods as a result of a new inspection system that allowed companies to perform their own food safety checks, and which ultimately lead to the listeriosis outbreak that killed seven people. Additionally, privatization of hospitals in the U.S., Iran, Kuwait and other countries around the world has led to the ghettoization of public hospitals, and the privatization of government assets in New Zealand during the height of globalization deteriorated the country's social infrastructures. Currently, there are hair-raising discussions that may allow private industry to gain access to the financial share of the already eroded public health system in Canada, ignoring Romanow's historic consultation and report.

Without getting into any specific arguments, it could be useful to look at a few examples that support the nationalization movement: nationalization of gas in Venezuela, nationalization of healthcare in Cuba; the Northwest Ordinance of 1789/ the Louisiana Purchase of 1803 that put vast amounts of territory in the U.S. in the public domain; nationalization of primary education in most countries to battle illitracy; and the nationalization of higher education in many European countries, which has had the effect of guranteeing social advancement to their citizens.

Perhaps it is time to spark new public debate regarding the implications of this movement, and to begin to forge new priorities that put public needs before the convenience of politicians and the private sector. 